\title{
VLADIMIR PRELOG E A ESTEREOQUíMICA DAS MOLÉCULAS ORGÂNICAS - UM CENTENÁRIO DE NASCIMENTO
}

\author{
Claudia M. Rezende* \\ Instituto de Química, Universidade Federal do Rio de Janeiro, 21945-000 Rio de Janeiro - RJ, Brasil
}

Recebido em 25/7/06; aceito em 9/11/06; publicado na web em 28/5/07

\begin{abstract}
VLADIMIR PRELOG AND THE STEREOCHEMISTRY OF ORGANIC MOLECULES: A CENTENARY OF BIRTH. The Croatian chemist Vladimir Prelog shared in 1975 the Nobel Prize in chemistry with J. W. Cornforth for his research into the stereochemistry of organic molecules and reactions. His studies gave new horizons to the comprehension of steric effects on the reactivity of mediumsized rings, to conformational analysis and to the stereospecificity associated to asymmetric syntheses. Prelog made important contributions to enzyme chemistry and to the structure elucidation of alkaloids and of antibiotics from microorganisms, but probably his most famous work is the CIP system for assigning the stereochemistry of chiral centers.
\end{abstract}

Keywords: Vladimir Prelog; stereochemistry; organic molecules.

Em 2006 comemorou-se o centenário de nascimento de Vladimir Prelog, químico croata laureado com o Prêmio Nobel de Química em 1975, juntamente com John Cornforth, pela sua grande contribuição ao estudo da estereoquímica das moléculas orgânicas.

Na Figura 1 pode-se ver a imagem de uma mulher, concebida pelo pintor suíço Hans Erni, a pedido de Prelog, e que recebeu o nome de "Rassi-maid", em alusão a "racemate", palavra inglesa usada para designar uma mistura equimolar de um par de enantiômeros e que não exibe atividade ótica. Esta gravura foi oferecida por Prelog aos colegas e amigos em agradecimento às homenagens recebidas na ocasião da premiação do Nobel.

Segundo Prelog, para compreender a estereoquímica com base no fenômeno da quiralidade, seria necessário unir a inteligência humana, as mãos esquerda e direita e os dois objetos assimétricos mais simples do espaço tridimensional, os tetraedros enantiomorfos.

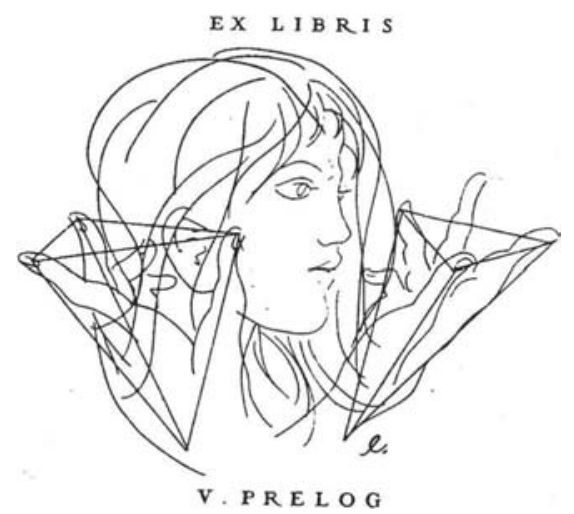

Figura 1. Ex- libris de Vladimir Prelog concebido por Hans Erni

O termo quiral vem do grego cheir, que significa mão, o mais familiar dos objetos assimétricos. Uma figura quiral não se sobrepõe a sua imagem no espelho e ambas são chamadas de enantiomorfos ou enantiômeros. Reconhecemos bem este fenômeno quando tentamos ler uma palavra pelo espelho retrovisor do automóvel. Com certa curiosidade, percebemos que esta imagem é contrária à que observamos diretamente. Prelog bem retratou esta visão ao assinar,

*e-mail: crezende@iq.ufrj.br em 1966, de trás para frente, a Declaração de Bürgenstock (Figura 2), na segunda reunião da EUCHEM Conference on Stereochemistry, mais conhecida como Bürgenstock Conference, um dos mais conceituados encontros científicos mundiais sobre estereoquímica e que ocorre na Suíça. Foi lá que Cahn, Ingold e Prelog formularam as regras da nomenclatura absoluta $R$ e $S^{1}$.

Prelog nasceu em 1906, em Sarajevo, província da Bósnia pertencente à monarquia austro-húngara. Em 1914, viveu um episódio que marcou sua vida. Ainda menino, fora incumbido pela escola de portar-se em um cordão de isolamento durante a visita do arquiduque, o Príncipe Ferdinand e sua esposa, que chegariam de carruagem. Prelog deveria espalhar flores à frente da comitiva. Durante o evento teve o choque de presenciar o assassinato do príncipe, fato que o tornou totalmente avesso às manifestações mais violentas de qualquer causa ou natureza.

Iniciou seus estudos na cidade de Zagreb, capital da Croácia, no ano de 1915, aos cuidados de uma tia paterna após a separação de seus pais. Já aos 12 anos teve o primeiro contato com as ciências da experimentação realizando no laboratório da escola práticas de destilação, recristalização e geração de $\mathrm{O}_{2}$ e $\mathrm{H}_{2}$.

Após a incorporação da Croácia à Iugoslávia, em 1918, Prelog mudou-se com o pai para a cidade de Ozigek. Sob orientação de seu professor de química, publicou seu primeiro trabalho científico em um respeitado periódico alemão ${ }^{2}$, a despeito de suas críticas posteriores sobre a qualidade das publicações da época, haja vista a sua própria. Terminou seus estudos ginasiais na cidade de Zagreb, quando seu pai assumiu a disciplina de História Moderna na Universidade. Ainda sob influência paterna, decidiu-se a cursar a graduação em Química no Instituto Tcheco de Tecnologia, em Praga.

Até o segundo ano, o curso mostrava-se bastante enfadonho exceto pelas aulas de Franz Wald e suas idéias originais sobre os fundamentos da química e pela leitura de textos científicos variados, como os de Ostwald, Mach e Poincaré.

Foi durante as aulas experimentais de química orgânica que Prelog despertou verdadeiramente para os desafios da química que estariam por vir. Emil Votoček era o professor responsável pela disciplina e supervisor do laboratório de Bernard Tollens, que se dedicava à química dos açúcares. Contava com um jovem e dedicado assistente, Rudolf Lukeš, apenas 8 anos mais velho que Prelog, que ansiava por uma carreira independente. Com este, Prelog apren- 


\section{Buergenstock Declaration}

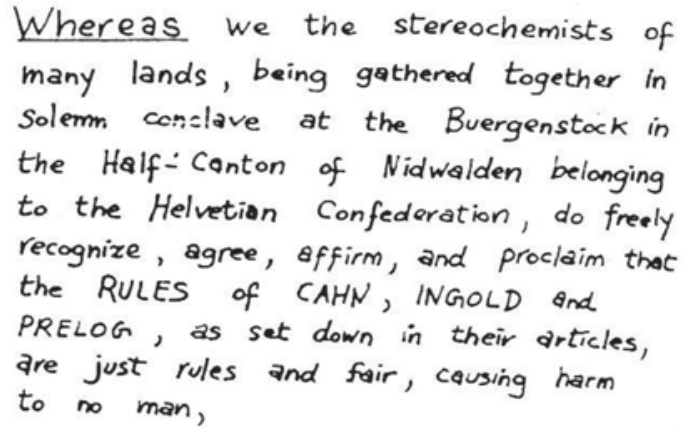

Whereupon we do affirm that any infringement of this Agreement shall

Figura 2. A Declaração de Bürgenstock foi escrita e assinada por Kurt Mislow e Andre Dreiding na Second Bürgenstock Conference (1966) e Robert Cahn, Christopher Ingold e Vladimir Prelog serviram de testemunhas deu toda a sistemática da química orgânica: furar rolhas, soprar vidros, organizar a literatura, conhecer as classes de substâncias e entender seus mecanismos de reação até aplicá-las ao principal interesse de Lukeš, a química dos alcalóides.

Naquela época, a análise elementar de uma substância necessitava até $300 \mathrm{mg}$ de material, o que implicava em sínteses de grande escala e, conseqüentemente, no uso de matéria-prima barata. $\mathrm{O}$ primeiro projeto de Prelog foi o estudo da reação da succinimida com brometo de fenil magnésio. Para tal, preparou o anidrido succínico a partir de etanol, 1,2-dibromoetano e 1,2-dicianoetano; metilamina a partir de formaldeído e cloreto de amônia e bromobenzeno pela bromação de benzeno. Um dos produtos da reação, o $\mathrm{N}$-metil-2,5-difenilpirrol, fora obtido na forma de magníficos cristais triboluminescentes e fluorescentes que deixaram Prelog excitado com a possibilidade de descobrir substâncias jamais preparadas por outros pesquisadores ${ }^{3}$.

Após a colação de grau, com distinção, Prelog passava por privações financeiras e havia um cenário de recessão econômica por toda Europa, o que impediu seu aproveitamento imediato na academia. Precisava obter seu doutoramento com algum subsídio financeiro. O convite de Gothard J. Dríza, um jovem e empreendedor colega de Lukeš que almejava produzir produtos químicos ainda não comercializados, veio a calhar. Na casa improvisada como laboratório, no subúrbio de Praga, produziram sulfito de amônia para salões de beleza, cloroacetofenona para uso como gás lacrimejante e até produtos mais exóticos à base de telúrio para as Forças Armadas. Em 1929, obteve seu doutoramento na determinação estrutural da aglicona do glicosídeo rhamnocolvolvulina, sob a orientação de Votocek ${ }^{4}$ e posteriormente tornou-se orientador de Dríza.

Entre todos os afazeres, Prelog dedicava-se à química dos alcalóides e tinha a quinina como alvo. Sendo o principal agente antimalarial da época, imaginou que sua contribuição poderia extrapolar os limites da química e trazer-lhe ainda alguma ajuda financeira. Além disso, Prelog havia contraído malária durante o serviço militar que prestou à Marinha Iugoslava por 9 meses.

O estudo dos alcalóides das raízes de Cinchona era um desafio interessante. A configuração destas moléculas não havia sido corretamente determinada, até então, e não se dispunha de material de partida adequado para produção em larga escala do núcleo quinuclidina da quinina (1). Aminas bicíclicas semelhantes à quinuclidina, com átomo de nitrogênio na junção dos anéis, haviam sido pouco estudadas e Prelog deu sua primeira grande contribuição científica ao escolher este núcleo para estudo, tema de pesquisa que se estendeu por quase 20 anos.

Dois anos após casar-se com Kamila Vítek, em 1933, ingressou na Universidade de Zagreb como professor assistente. O salário era baixo, faltava pessoal treinado e o laboratório era precário, mas Prelog conseguiu o apoio financeiro de um pequeno laboratório farmacêutico em troca de consultoria, interessado em produzir fármacos não disponíveis no mercado. Durante a $2^{\mathrm{a}}$ Guerra Mundial, o Kastel, Ltd. já era reconhecido na Iugoslávia e foi nacionalizado. Sob o nome de Pliva, veio a tornar-se a maior companhia farmacêutica iugoslava com um grande centro de pesquisas.

A busca por quimioterápicos para tratamento de infecções microbianas era uma atividade em amplo desenvolvimento e bastante competitiva. Em 1934, Gerhard Domagk demonstrou que o corante azóico prontozil atuava eficazmente em ratos infectados por estreptococos. Com base em resultados de testes, Prelog propôs à Kastel, Ltd. a síntese de um análogo do prontosil ${ }^{5}$. Nesta mesma época, pesquisadores do Instituto Pasteur, em Paris, comprovavam que era a sulfanilamida (2), um metabólito do prontozil, o agente ativo responsável pela atividade anti-bacteriana. A sulfanilamida não tinha nenhuma síntese coberta por patente e não 
era um produto comercial. Prelog, para sua sorte, já tinha desenvolvido sua síntese e rapidamente ofereceu à Kastel, Ltd.<smiles>C=C[C@H]1CCN2CC[C@H]1C2C(O)c1ccnc2ccc(OC)cc12</smiles>

1<smiles>Nc1ccc(S(N)(=O)=O)cc1</smiles>

2
Em pouco tempo o medicamento foi comercializado sob o nome de Streptazol ${ }^{\circledR}$ (Figura 3) e rendeu a Prelog retorno financeiro para si e seu laboratório.
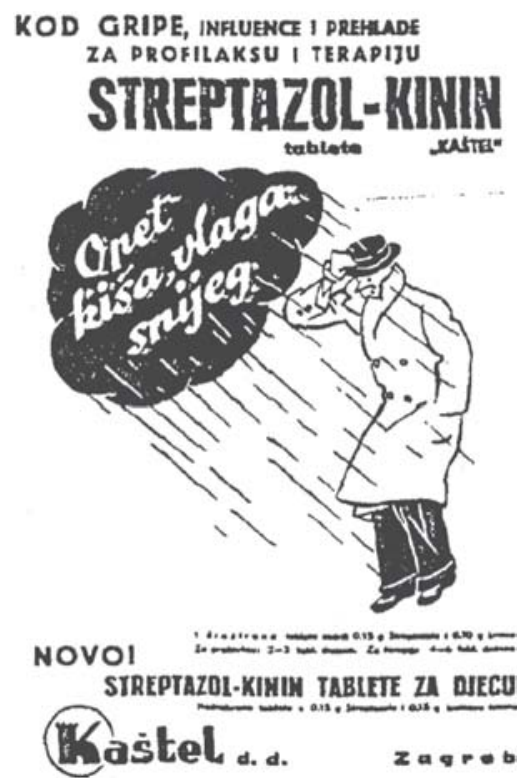

Figura 3. Propaganda impressa de medicamento Streptazol ${ }^{\circledR}$, produzido pela Kastel, Ltd

Com suas novas condições, pode então realizar o antigo sonho de conhecer a química fora das fronteiras da Iugoslávia. Em 1937, partiu para um estágio no laboratório do eminente químico Leopold Ruzicka, no Instituto Federal de Tecnologia de Zurique (ETH), na Suíça. Além de compatriota, Ruzicka já havia se projetado internacionalmente por sua contribuição à química dos terpenos e hormônios esteroidais, o que veio a lhe render o prêmio Nobel em Química ${ }^{6}$. Desta colaboração resultou a publicação de um trabalho sobre o triterpeno ácido quinóvico ${ }^{7}$.

Em 1940, Prelog tornou-se professor associado. Ampliou os estudos dos alcalóides da Cinchona sintetizando misturas diastereoisoméricas de derivados do 6-metoxirubanol ${ }^{8}$, quinuclidina e derivados ${ }^{9}$ e outros núcleos nitrogenados ${ }^{10}$. Em 1941, publicou a primeira síntese do hidrocarboneto adamantano (3) ${ }^{11}$. Ainda durante sua graduação, Prelog presenciou com Stanislav Landa e R. Lukeš a descoberta de um hidrocarboneto terpênico de fórmula molecular $\mathrm{C}_{10} \mathrm{H}_{16}$, com ponto de fusão de $266^{\circ} \mathrm{C}$, o que foi recebido por Lukeš com muita estranheza. Durante a análise elementar do material ocorreu uma sublimação e o aparecimento de cristais brilhantes, o que levou Lukeš a propor imediatamente o esqueleto rígido da molécula do adamantano. Como Landa nunca descreveu este fato em suas publicações mas, sim, apoiou suas deduções em dados de difração de raio X, Prelog revelou mais tarde que esta foi a sua verdadeira inspiração para o estudo da síntese do adamantano, obtido na escala de gramas e realizada em parceria com Ratijov Seiwerth ${ }^{11}$.

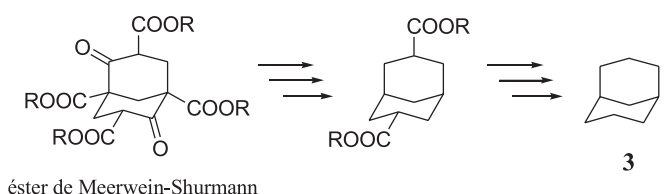

Figura 4. Representação simplificada da síntese do adamantano partindo de éster de Meerwein-Schurmann

Com a deflagração da guerra Prelog recebeu, em 1940, a visita de um importante pesquisador alemão, Franz Hoffmann, conhecido pela síntese e polimerização do isopreno para produção da borracha natural ${ }^{12}$, usada na $1^{\mathrm{a}}$ Guerra Mundial. Assim como Prelog, Hoffmann também era avesso à situação política européia vigente e acabou contando a Prelog algumas histórias curiosas do período. Carl Duisberg, o industrial e fundador da IG Farben, a grande mantenedora de produtos químicos da Alemanha na $2^{\mathrm{a}}$ Guerra Mundial, insistia com Hoffmann para trazer o famoso Emil Fischer para a empresa. Enviou-o a Berlim com a incumbência de oferecer a Fischer 5\% dos royalties na venda do medicamento bromural $(\alpha-$ bromoisovaleriluréia). Fischer foi quem realizou a primeira síntese do cloreto do $\alpha$-bromo ácido, seu material de partida. Hoffmann achou tudo aquilo um despropósito pois Fischer nada tinha a ver com o processo de produção. Muito a contragosto foi ter com Fischer que, para seu total espanto, não aceitou os $5 \%$ mas pediu $10 \%$ ! Este acontecimento pôs abaixo a conhecida observação do pai de Fischer, um grande homem de negócios: "Este menino é muito estúpido para seguir o ramo dos negócios; assim, em nome de Deus, deixem-no estudar".

Em 1941, o exército alemão invadiu Zagreb e Prelog ficou em uma situação preocupante. Os nazistas vinham usando estrangeiros como mão-de-obra escrava, e ele poderia ser uma peça importante nas instalações químicas da I.G. Farben. Richard Kuhn, presidente da Sociedade Química Alemã, atento ao extenso número de publicações em periódicos alemães de Prelog, convidou-o para uma série de palestras na Alemanha. Na oportunidade, Prelog contactou Ruzicka em Zurique, que conseguiu vistos de entrada na Suíça para o casal. Em dezembro de 1941, Prelog e a mulher deixaram a Iugoslávia para o resto de suas vidas.

Logo após sua chegada a Zurique, o grupo de Ruzicka sofreu fortes perdas com a emigração de colaboradores de origem judaica para os EUA. Dentre estas perdas houve a de Leo Sternabach, que se tornou conhecido pela síntese dos psicoativos benzodiazepínicos Valium e Librium ${ }^{13}$, na Hoffmann-La Roche (Nova Jersey), que mudaram o paradigma no tratamento das doenças mentais.

Prelog iniciou sua colaboração trabalhando com extratos lipídicos de origem animal e isolou os esteróis $\mathbf{4 a}$ e $\mathbf{4 b}$, de esqueleto androstano ${ }^{14}$. Estes esteróis tiveram suas estruturas confirmadas por síntese e apresentaram um odor almiscarado semelhante à civetona, a "musk" cetona monocíclica de 15 membros isolada das glândulas do gato da Algália (civet), cuja estrutura havia sido determinada por Ruzicka. Com o financiamento da CIBA (Basiléia), Prelog estudou a composição química de extratos de urinas de cabras prenhas, usados no isolamento de hormônios estrogênicos e disponíveis em milhares de litros. Ao lado de diversos metabólitos, identificou substâncias voláteis do grupo das iononas, possíveis produtos de degradação de carotenóides ${ }^{15}$.

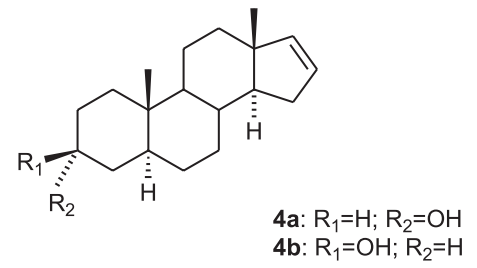


A preparação de hormônios esteroidais dependia da disponibilidade de colesterol, escasso durante a guerra. Prelog viu a possibilidade de reunir sua experiência e interesse em alcalóides e propôs o uso da solanina como material de partida. Determinou a configuração do núcleo esteroidal de sua aglicona, a solanidina $(\mathbf{5})^{16}$, comparando-a ao colesterol.

$\mathrm{O}$ isolamento provocado pela guerra exigia bom uso do almoxarifado. Ruzicka dispunha de grandes quantidades de estriquinina, Robert Robinson tinha vários trabalhos sobre a estrutura química deste alcalóide mas o tema estava em aberto. Prelog e Stefan Szpilfogel propuseram que o anel E da estriquinina não era de 5 membros como havia sugerido Robinson, e sim de 6 membros. Apesar desta certeza, erraram na proposta estrutural ${ }^{17}$, que foi prontamente combatida por Robinson, que afirmou: "Se Prelog e Szpilfogel foram capazes de gerar uma nova proposta de 6 membros para o anel $\mathrm{E}$ da estriquinina, a fórmula que deve ser considerada é III" (ou 6) ${ }^{18}$. Esta estrutura foi posteriormente confirmada por Robert B. Woodward, em uma das mais belas concepções de síntese orgânica da literatura ${ }^{19}$.

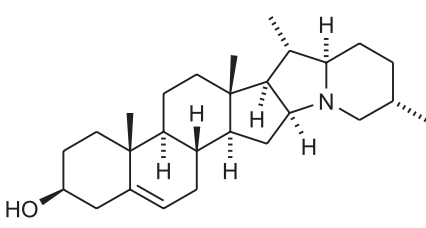

5

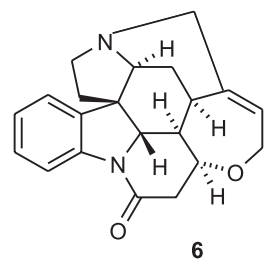

Envergonhado, Prelog tratou de refazer sua imagem, o que resultou em trabalhos como a determinação da configuração dos carbonos 3 e 4 do núcleo quinuclidínico dos alcalóides majoritários das raízes de Cinchona $^{20}$ e a resolução cromatográfica do racemato da base de Tröger, o primeiro exemplo de uma substância oticamente ativa tendo o átomo de $\mathrm{N}$ trivalente como centro quiral ${ }^{21}$.

No fim da guerra, em 1945, Prelog foi promovido a professor associado no ETH. Ruzicka estava fortemente envolvido com a ajuda humanitária aos países destroçados, o que acabou por afastálo do laboratório e permitiu que seus colaboradores diretos se envolvessem em projetos sem a sua participação. A esse fato somouse a visita de vários pesquisadores estrangeiros à Suíça no pósguerra, entre os quais Roger Adams, Louis Fieser, Maurice Janot e Robert Robinson. Com Janot, Prelog manteve uma profícua colaboração durante quase 10 anos, estudando metabólitos de plantas exóticas oriundas das colônias francesas, de onde isolaram e determinaram a estrutura da corinanteína ${ }^{22}$ e da cinchonamina ${ }^{23}$, entre outros alcalóides. A reunião destes estudos gerou conexões biogenéticas importantes entre alcalóides indólicos e quinolínicos das raízes da Cinchona, base de diversos trabalhos posteriores na área. Em Zurique, tiveram sucesso no estudo de alcalóides da Erythrina, isolando e determinando a estrutura da erisodina e eritralina, entre outros ${ }^{24}$

Dentre as colaborações internas, a mais expressiva foi com Oskar Jeger, um antigo colaborador de Ruzicka. Desenvolveram reações de redução de derivados sulfurados de carbonila usando níquel de Raney ${ }^{25}$ e investigaram alcalóides de Veratrum $^{26}$. Através do estudo estrutural da cevina, acabou por aproximar-se de dois grandes químicos, Derek H. R. Barton, do Birbeck College em Londres e Robert B. Woodward, de Harvard.

O jovem Woodward havia deixado uma profunda impressão em Ruzicka e Prelog por ocasião de sua conferência no ETH, em 1948. Incompreendido e considerado arrogante pelos colegas americanos, acabou por se aproximar de Prelog e os dois estabeleceram uma forte amizade que só terminou com o falecimento de Woodward, em 1979.
A colaboração com Barton se deu em um clima mais competitivo. Ruzicka e Barton disputavam as novidades no campo dos triterpenos tetracíclicos. Prelog, com seu caráter cordial e colaborativo era crédulo na parceria científica e achava perda de tempo a duplicação de esforços desta natureza. Como resultado, Barton, Prelog, Jeger e Woodward publicaram a determinação estrutural da cevina. Dos 13 centros assimétricos deste alcalóide apenas um foi atribuído erroneamente. Por ironia do destino, usando análise conformacional ${ }^{27}$.

$\mathrm{O}$ trabalho com a cevina marcou o encerramento das atividades de Prelog na química dos alcalóides.

A abertura dos portões suíços para o mundo no pós-guerra favoreceu a rápida inserção de seus pesquisadores no contexto científico internacional, o que teve fortes implicações na carreira de Prelog. A partir da década de 50, ele abriu frentes de pesquisa importantes na área da estereoquímica conceitual e sua aplicação no estudo de metabólitos de microorganismos, na enzimologia e no comportamento dos anéis de médio porte, contribuições que acabaram por levá-lo à premiação do Nobel.

Cronologicamente, a primeira destas contribuições foi no estudo dos anéis de 9 a 11 átomos de carbono. O comportamento anômalo de sua reatividade frente aos anéis menores de 5 e 6 membros, bem como aos maiores de 12 membros, não se justificava pelas idéias vigentes de Robinson-Ingold, conforme já apontado por Ruzicka. Para uma investigação mais aprofundada, havia necessidade de desenvolver uma metodologia eficiente para a síntese destes compostos. A Dupont detinha a patente do melhor processo, que apresentava o pífio rendimento de $6,5 \%$ pela reação do ácido sebácico com sódio fundido em xileno a quente, em um moinho coloidal. Na sua ausência, Prelog repetiu a reação sob forte agitação resultando num rendimento de $40 \%$ e a metodologia pôde então ser aplicada para a obtenção de aciloínas de ciclos variados sem a necessidade de alta diluição (Figura 5). Apesar da excitação com o resultado obtido, Prelog teve de dividir os louros com o grupo de pesquisa da Fimenich \& Company, de Genebra, que estava pedindo o depósito da patente ${ }^{28}$. Para sua sorte, o interesse deste laboratório estava nos ciclos maiores, relacionados ao aroma almiscarado.

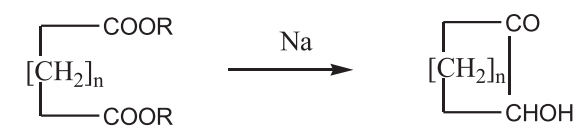

Figura 5. Aciloínas a partir de di-ésteres de cadeia longa fundidos com sódio

A reunião dos dados levou Prelog a propor que o comportamento dos anéis medianos baseava-se em um efeito conformacional, ao qual deu o nome de "constellational effect", apoiado na proposta Friedrich Ebel. Estes resultados foram apresentados no primeiro "Centenary Lecture of the Chemical Society", em 1949, e tiveram plena aceitação da comunidade científica ${ }^{29}$. Mais tarde, Barton fez uma cuidadosa análise dos dados estruturais disponíveis para terpenos e açúcares e, associando-os ao trabalho pioneiro de Walter $\mathrm{N}$. Haworth, estabeleceu o que passou a ser aceito como análise conformacional (o termo constelação foi abolido) ${ }^{30}$. Outras contribuições importantes de Prelog no comportamento de anéis medianos foram na estabilidade de ciclos insaturados ${ }^{31}$, em metaciclofanos ${ }^{32}$ e em quinonas ${ }^{33}$. Prelog definiu, assim, os limites das regras de Bredt.

Com renome internacional Prelog partiu, em 1950, para a Universidade de Notre Dame, em Indiana, como "Reilly Lecture" a convite de Charles C. Price, a despeito do afastamento de sua família que agora contava com o pequeno filho Jan, com um ano de idade. Visitou diversas universidades americanas onde proferiu conferências e estabeleceu parcerias e amizades. 
Ao retornar a Zurique, Prelog trazia na bagagem o tentador convite de se transferir para a Universidade de Harvard. Ruzicka imediatamente usou de sua influência para promovê-lo a "Full Professor", fato que causou constrangimento no grupo, principalmente pela dedicação de alguns colaboradores. Placidus A. Plattner ${ }^{34}$, um dos mais antigos colaboradores de Ruzicka e a quem Prelog deveu o ingresso na área de metabólitos microbianos, desvinculouse do ETH para assumir o cargo de diretor de pesquisa na HoffmannLa Roche, na Basiléia.

Em 1951, partiu novamente para os EUA a convite da "American Chemical Society", que comemorava seu jubileu de diamante. Lá, trocou idéias com Arthur C. Cope sobre as recém-descobertas reações transanulares em anéis medianos ${ }^{35}$. O grupo de Prelog havia observado, pela primeira vez, que a reação do trans-ciclodeceno (7) com ácido perfórmico produzia, entre outros produtos, ciclodecano-1,6-diol (8) e 6-hidroxiciclodeceno $(\mathbf{9})^{36}$. Justificou estes produtos pela formação do carbocátion gerado na abertura do epóxido intermediário, seguido da migração 1,5 de um íon hidreto. Cope havia detectado produtos semelhantes com ciclooctenos. Prelog investigou a presença deste possível carbocátion na acetólise de cicloalquil- $p$-toluenossulfonatos ${ }^{37}$, estudo realizado em paralelo por H. C. Brown ${ }^{38}$. Tornou a inovar quando utilizou os isótopos ${ }^{14} \mathrm{C} \mathrm{e}{ }^{2} \mathrm{H}$ para marcar o curso destas reações e confirmar a ocorrência de rearranjos não-clássicos de hidretos nestes $\operatorname{ciclos}^{39}$.

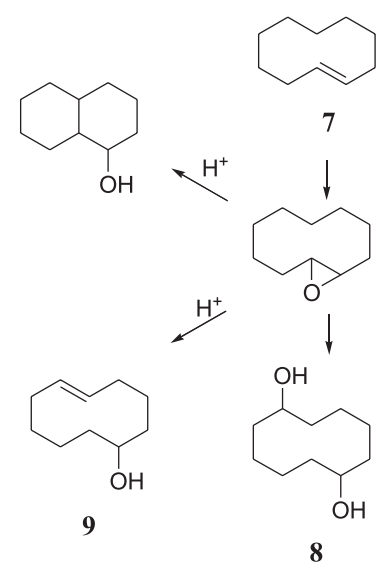

Figura 6. Reações transanulares observadas por Prelog e colaboradores com o ciclodeceno

A química sofria fortes alterações a partir da década de 50. A espectroscopia tomava o lugar dos métodos químicos clássicos na elucidação estrutural. As técnicas cromatográficas desenvolviamse velozmente, facilitando o trabalho de isolamento na química de produtos naturais e na síntese. A obtenção de moléculas polifuncionais e a síntese assimétrica passavam a contar com metodologias de planejamento racional e modelos para o cálculo teórico de interações físico-químicas. Além disso, os eventos observados nos organismos vivos começavam a ser compreendidos em nível molecular.

Prelog soube aproveitar os avanços e, com o apoio de Ruzicka, reestruturou o laboratório com novos equipamentos, mas mantevese fiel à química dos produtos naturais apoiada na síntese e na compreensão dos fenômenos estereoquímicos. Com a saída de Plattner e apoiado pela CIBA, assumiu os estudos sobre metabólitos microbianos, particularmente aqueles com atividade antibiótica. Logo descobriu que culturas de microorganismos eram fontes ricas de moléculas cíclicas complexas, tema a que se dedicou por mais de 15 anos. Deparou-se com algumas substâncias que havia sintetizado no laboratório com Ruzicka, em busca dos odores almiscarados, até então tidas como raras mas de ocorrência comum em micro- organismos. A primeira delas foi a narbomicina, uma lactona de 14 membros (10). Por degradação oxidativa obteve (11), conhecida posteriormente como lactona de Prelog-Djerassi ${ }^{40}$, que se tornou um importante intermediário na síntese de macrolídeos. A contribuição de Carl Djerassi para a determinação da configuração absoluta de alguns destes antibióticos, um ano após o trabalho de Prelog parece ter sido a causa do apelido dado pela comunidade científica à lactona $\mathbf{1 1}^{41}$. Posteriormente, Prelog costumava rir muito ao contar um episódio ocorrido nos EUA, quando um aluno o interpelou e disse: " Eu o conheço, você é Djerassi-Prelog!".

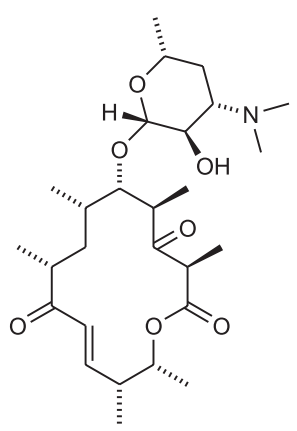<smiles>C[C@H]1C[C@@H](C)C(=O)O[C@H]1[C@H](C)OC(=O)O</smiles>

11

10

Outras importantes contribuições nesta área foram: o isolamento de macrolídeos de 32 membros, como a nonactina ${ }^{42}$, e sua posterior aplicação em eletrodos seletivos de íons, por Wilhelm Simon; a determinação estrutural da equinomicina ${ }^{43}$, que veio a se destacar por sua complexação com ácidos nucléicos; a descoberta do complexo agonista-antagonista dos antibióticos da classe das ferrimicinas ${ }^{44}$; a descoberta da boromicina ${ }^{45}$, o primeiro produto natural contendo o átomo de boro em um esqueleto orgânico e finalmente a determinação estrutural dos antibióticos da classe das rifamicinas, cuja história será melhor detalhada a seguir.

Em 1969, Prelog foi convidado pelo laboratório farmacêutico Lepetit, em Milão, para colaborar na determinação estrutural de uma classe de antibióticos recém-descoberta, as rifomicinas (que viriam a se chamar rifamicinas, em atendimento às leis de patente da época). Passou a incumbência ao seu mais novo aluno de doutorado, o jovem Wolfgang Oppolzer, que veio a ser um dos grandes nomes da química estereosseletiva de reações de cicloadição ${ }^{46}$. Numa corrida contra o tempo, Oppolzer e Prelog fecharam e publicaram a determinação estrutural de diversos derivados das rifomicinas sem os dados da análise de difração de raio $\mathrm{X}^{47}$, inicialmente solicitado ao grupo de Yale e posteriormente a Alessandro Vaciago, de Roma. Pouco tempo depois, Vaciago telefonou para Prelog informando que os dados das análises de difração de raio $\mathrm{X}$ estavam de acordo com suas propostas e que estariam sendo encaminhados para sua apreciação. Qual não foi a surpresa de Prelog ao verificar, em uma análise mais detalhada das imagens, que as duas ligações duplas determinadas como $\alpha, \beta$ - cis e $\gamma, \delta$ - trans do grupo carboxiamida da rifomicina $\mathbf{1 2}$ apresentavam-se na imagem como sendo a primeira trans e a segunda, cis. Não compreendendo o motivo, Prelog ligou para Vaciago e questionou as configurações dos modelos. Vaciago veio então a descobrir que durante o transporte, feito por um taxista até o laboratório fotográfico, o modelo sofreu avarias numa freada brusca e o fotógrafo o recompôs erroneamente! As rifomicinas foram rebatizadas posteriormente como rifamicinas já que havia um outro antibiótico patenteado com o nome de rufomicina.

No campo dos antibióticos destaca-se ainda a colaboração com o cientista brasileiro Oswaldo Gonçalves de Lima, químico e professor fundador do Instituto de Antibióticos da Universidade do Recife, reconhecido pelo seu importante trabalho sobre a atividade antimicrobiana do lapachol. Gonçalves de Lima encaminhou a 
Prelog uma substância antibiótica isolada de Capraria biflora (Scrophulariaceae), de coloração violácea intensa, cuja estrutura foi determinada em 1963, por transformação química e RMN. Tratava-se da biflorina, um diterpeno incomum com esqueleto naftoquinona $(\mathbf{1 3})^{48}$.

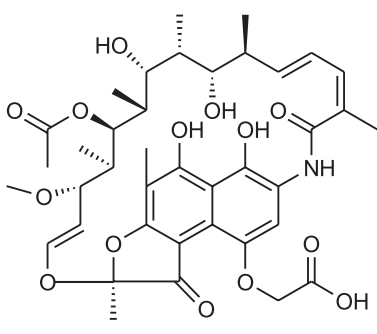

12<smiles>CC(C)=CCCC1=COC2=C(C)C(=O)C(=O)c3c(C)ccc1c32</smiles>

13
Ainda nos anos 50, Prelog iniciou suas pesquisas no campo da síntese assimétrica, tendo como alvo a reação de $\alpha$-cetoésteres com reagentes de Grignard. Alexander McKenzie observara inúmeros casos de indução assimétrica, mas não havia determinado a causa da enantiosseletividade. Com base nas idéias mais modernas sobre conformações energeticamente mais estáveis, Prelog reanalisou os dados de McKenzie e formulou uma regra geral contemplando a relação entre os $\alpha$-hidroxiésteres quirais formados e a face preferencial para o ataque do reagente de Grignard, considerando a posição e volume dos substituintes ${ }^{49}$ (Figura 7). Em seguida, sintetizou uma série de derivados do ácido atrolático ${ }^{50}$ e aplicou a regra para a determinação da configuração de diversos álcoois secundários de origem natural. Seu único trabalho em colaboração com John Cornforth ${ }^{51}$ foi sobre a determinação da configuração absoluta do (-)-linalol (que provaram ser $R$ e não $S$, como anteriormente proposto por Prelog), aplicando esta metodologia ${ }^{52}$.

Face $S i$

$$
\mathrm{R}_{2} \mathrm{MgX}
$$<smiles>[R]C(C)(C)C(=O)O[C@@](C)([NH3+])O</smiles>
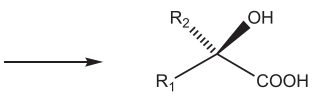

(R)-(-) ácido atrolático

$$
\text { Face } R e
$$$$
\mathrm{R}_{2} \mathrm{MgX}
$$<smiles>[R]C(C)(C)C(=O)O[C@@]([R])(F)Cl</smiles>
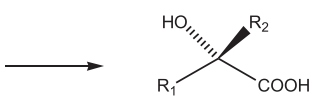

(S)-(+) ácido atrolático

$$
\mathrm{R}_{1}=\text { fenila; } \mathrm{R}_{2}=\text { metila }
$$

$\mathrm{G}=$ grupo mais volumoso; $\mathrm{M}=$ grupo médio; $\mathrm{P}=$ grupo pequeno

Figura 7. Proposta para a enantiosseletividade da reação de $\alpha$-cetoésteres com reagentes de Grignard

Prelog alçou um de seus mais altos vôos ao aplicar seus estudos de estereosseletividade às reações enzimáticas, na redução de carbonilas utilizando culturas de células. Em uma reunião de talentos e com o apoio da CIBA, que vinha empregando microorganismos na oxidação de esteróis para produção de hormônios corticosteróides, as reduções foram conduzidas inicialmente com cetonas e dicetonas cíclicas de 6 membros. Um exemplo foi a redução de 1,4-decalinadionas diastereoisoméricas em culturas de Curvularia falcata, cujo álcool quiral obtido invariavelmente apresentava a configuração $S$, qualquer que fosse a configuração dos centros estereogênicos nas moléculas. A aproximação para transferência do hidrogênio dava-se sempre pela face $R e$ da carbonila.
Esta constatação levou Prelog a propor um modelo espacial para a reação enzimática, comprovado alguns anos depois por Minor J. Coon e Hans Duner pelo isolamento das oxido-redutases responsáveis pelo processo de redução ${ }^{53}$.

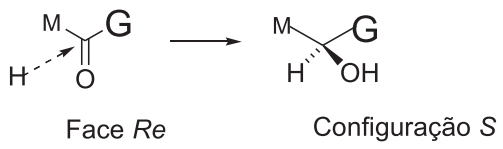

Figura 8. Proposta para a aproximação espacial na redução estereosseletiva de cetonas com o microorganismo Curvularia falcata

Mas foi o sistema Cahn-Ingold-Prelog (CIP) de determinação de configuração absoluta que lhe rendeu maior fama.

Tudo começou com a participação de Prelog nas reuniões da IUPAC, em substituição a Votocek, para a normalização da nomenclatura de química orgânica. A área da estereoquímica contava quase que somente com a nomenclatura desenvolvida por Emil Fischer para descrever configurações relativas em açúcares e aminoácidos. Em 1951, Robert S. Cahn e Christopher Ingold apresentaram uma nova proposta para os descritores D e L. Durante o encontro anual da ACS, em 1954, houve um simpósio sobre estereoquimica dinâmica e Prelog, com sua ativa participação, acabou sendo convidado por Cahn e Ingold para discutir suas regras em função das fortes críticas que realizou. Dois anos depois, os três lançaram seu primeiro sistema ${ }^{54}$, que apesar de muito criticado foi adotado pelos editores do Beinstein's Handbuch der Organischen Chemie. Sua extensiva aplicação mostrou alguns de seus pontos falhos e levou à publicação de um segundo trabalho, que corrigia e expandia a aplicação das regras ${ }^{55}$. Após a morte de Cahn e Ingold, Prelog publicou um terceiro trabalho com G. Helmchen, discutindo as bases geométricas do sistema e ajustando o modelo anterior ${ }^{56}$. O sistema CIP havia se provado e, em 1984, o Institute for Scientific Information (ISI) classificou suas duas primeiras publicações entre o grupo seleto dos Citation Classics, entre os artigos mais citados na área. O CIP passava então a constar dos livros-texto de química orgânica, adotados nas melhores universidades.

Prelog deu continuidade aos trabalhos na estereoquímica definindo, em 1964, um novo tipo de estereoisomerismo. O conceito de cicloestereoisomerismo foi cunhado baseado na quiralidade bidimensional dos anéis, e aplicado inicialmente a cicloalaninas enantioméricas $(\mathbf{1 4 , 1 5})$, preparadas pelos russos Hans Gerlach e Yuri Ovchinnikov ${ }^{57}$. Seguiu daí para estudos sobre pseudoassimetria e enantioisomerismo geométrico e os exemplificou através da síntese de 16-18 $\mathbf{1 8}^{58,59}$
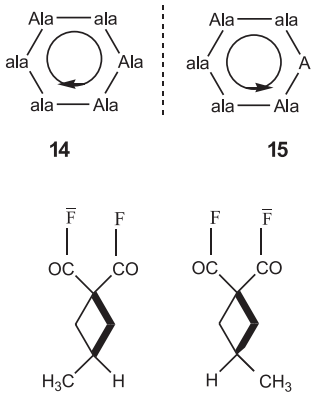

16

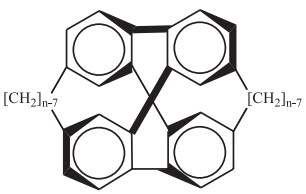

$18(n=13,14,15)$ 
Prelog sempre se mostrou um homem sensível, com um fino humor e muito colaborativo. Gostava de flores e mantinha seu escritório enfeitado por rosas e amarílis. Era fã de doces, especialmente com algum marasquino. Recebia os visitantes com sua pequena coleção de objetos quirais: cristais de quartzo, conchas e fósseis de amonita. Era sugestivo e persuasivo na discussão, credenciais importantes para seu carisma. Não tinha o hábito de beber, mas apreciava um bom brandy de ameixa ou mesmo um Riesling, com torradas. Era conhecido por suas histórias curiosas e anedotas, que gostava de contar até a madrugada.

Em 1957, no ano do lançamento da nave espacial Sputinik, assumiu a coordenação do laboratório de Ruzicka e viveu um dos períodos de maiores investimentos na ciência e tecnologia da Europa Oriental. Mas a glória veio com o infortúnio de ter de administrar as finanças e as idiossincrasias do grupo, que não eram suas especialidades. Usando de seu prestígio e poder de persuasão convenceu a diretoria do ETH a alterar a hierarquia institucional e passou a dividir estes encargos com outros colegas, que foram automaticamente promovidos e permaneceram no Instituto a despeito dos convites tentadores de outras instituições.

Prelog aposentou-se em 1976. Não havendo cargo institucional que contemplasse seu afastamento, registrou-se como aluno de pósdoutoramento com um projeto no estudo da separação de enantiômeros por extração em fase líquida. Com a experiência adquirida na síntese dos vespirenos (15), sintetizou uma série de éteres de coroa baseados no esqueleto do 9,9-espirobifluoreno ${ }^{60}$ e aplicou-os na construção de eletrodos enantiosseletivos por impregnação em cloreto de polivinila. Ésteres do ácido tartárico foram preparados a partir de álcoois quirais de cadeia longa e foi comprovada sua ação como plastificantes quirais, além de se mostrarem ionóforos seletivos para $\alpha$-aminoálcoois e ésteres. A aplicação destes ésteres em fases líquidas lipofílicas permitiu então a separação de enantiômeros por partição água/solvente orgânico ${ }^{61}$.

Prelog publicou ao redor de 400 trabalhos científicos e várias patentes. Suas memórias estão no livro "My 132 Semesters of Chemistry Studies", da série "Autobiographies of Eminent Chemists" da American Chemical Society ${ }^{62}$.

Foi eleito membro honorário de diversas sociedades científicas internacionais. Recebeu o Prêmio Nobel em Química em 1975 (Figura 9), que dividiu com John Cornforth, e foi agraciado com inúmeras distinções e honrarias: Werner Medal and Prize (Swiss Chemical Society), 1946; Stas Medal (Belgian Chemical Society), 1962; Medal of Honor (Rice University), 1962; Marcel Benoist Prize (Switzerland), 1965; Hanus Medal (Czech Chemical Society), 1966; A. W. Von Hofmann Memorial Medal (German Chemical Society), 1967; Davy Medal (Royal Society, London), 1968; Roger Adams Award (American Chemical Society), 1969; Paul Karrer Award (University of Zürich), 1974; Paracelsus Medal (Swiss Chemical Society), 1976; Order of the Yugoslavian Star, 1977; Order of the Rising Sun (Japan), 1977; Emil Votocek Medal (Institute of Chemical Technology, Prague), 1978; Hamilton Award (University of Nebraska), 1983; Evans Award (Ohio State University), 1983; Arun Guthikonda Memorial Award (Columbia University), 1984; Adolfo Quilico Medal (Società Chimica Italiana), 1985; Order of Yugoslav Banner with Golden Wreath, 1986 e Chirality Medal (Tübingen), 1992. Em 1998 foi escolhido pela "Chemical and Engennering News" entre os "Top 75 Distinguished Contributors to the Chemical Enterprise" entre 1923-1997.

Mesmo após sua partida para o ETH, manteve-se muito ligado às atividades científicas em Zagreb. Recebia cientistas croatas em seu laboratório e visitava com frequiência o Prelog's Zagreb School of Organic Chemistry, não negando suas origens.

Vlado, como era conhecido por seus amigos mais próximos, faleceu em 17 de janeiro de 1998.

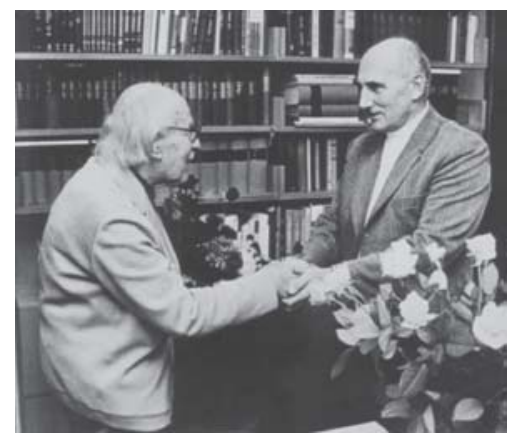

Figura 9. Prelog recebendo os cumprimentos de L. Ruzicka, por ocasião do Prêmio Nobel

\section{REFERÊNCIAS}

1. Nota de tradução - "Declaração de Buergenstock: Enquanto nós os estereoquímicos de muitas terras, reunidos em solene conclave no MeioCantão de Nidwalden, membro da Confederação Helvética, livremente reconhecemos, concordamos, afirmamos e proclamamos que as REGRAS DE CAHN, INGOLD, e PRELOG, conforme assentadas em seus artigos, são justas e lícitas, não causando dano a ninguém. Cada um de nós, sendo são de mente, livremente concorda em: 1. Observar as regras acima mencionadas em todos os casos em que sejam aplicáveis, e; 2 . Abster-se de usar outras regras que possam ter sido ou venham a ser propostas por outros poderes. Sobre o que afirmamos que qualquer infração deste Acordo será punida, em primeira instância com uma pena correspondente a 1 (um) copo de refrigério líquido a ser suprido às custas do infrator a todos os estereoquímicos presentes, e que, nas instâncias seguintes, o infrator será obrigado a ler os supramencionados artigos de CAHN, INGOLD e PRELOG em sua totalidade. Assinado, neste dia, Sexta Feira, 13 de maio de 1966, por A. Dreiding, fabricante de modelos, residente em Erlenbach, Suíça; K. Mislow, quirossofista, residente em Princeton, New Jersey e testemunhado por R. S. Cahn, Sir Christopher Ingold; V. Prelog e K. Mislow, quirossofista, como um modelo para todos os dissidentes com mentalidades críticas. André Dreiding estereossofista, estereotático".

2. Prelog, V.; Chem. Ztg. 1921, 45, 736.

3. Lukeš, R.; Prelog, V.; Collect. Czech. Chem. Commun. 1929, 1, 334.

4. Votocek, E.; Prelog, V.; Collect. Czech. Chem. Commun. 1929, 1, 55.

5. Prelog, V.; Kohlbach, D.; Collect. Czech. Chem. Commun. 1936, 8, 377.

6. http://nobelprize.org/nobel_prizes/chemistry/laureates/1939/ruzickalecture.pdf\#search=\%22ruzicka\%20nobel\%20lecture\%22, acessada em Outubro 2006.

7. Ruzicka, L.; Prelog, V.; Helv. Chim. Acta 1937, 20, 1570.

8. Prelog, V.; Stern, P.; Seiwerth, R.; Heimbach-Juhász, S.; Naturwissenschaften 1949, 28, 750.

9. Prelog, V.; Kohlbach, D.; Cerkovnikov, E.; Režek, A.; Piantanida, M.; Liebigs Ann. Chem. 1937, 532, 69.

10. Prelog, V.; Cerkovnikov, E.; Ustricev, G.; Liebigs Ann. Chem. 1938, 535, 37; Prelog, V.; Heimbach, S.; Cerkovnikov, E.; J. Chem. Soc. 1939, 677.

11. Prelog, V.; Seiwerth, R.; Chem. Ber. 1941, 74, 1644.

12. Hofmann, F.; Angew. Chem. 1920, 33, 77.

13. Sternbach, L. H.; Agents and Actions 1972, 2, 193.

14. Prelog, V.; Ruzicka, L.; Helv. Chim. Acta 1944, 27, 61.

15. Prelog, V.; Führer, J.; Hagenbach, R.; Frick, H.; Helv. Chim. Acta 1947, 30, 113.

16. Prelog, V.; Szpilfogel, S.; Helv. Chim. Acta 1942, 25, 1306.

17. Robinson, R.; Experientia 1946, 2, 28.

18. Woodward, R. B.; Cava, M. P.; Ollis, W. D.; Daeniker, I. U.; Schenker, K.; J. Am. Chem. Soc.1954, 76, 4749.

19. Prelog, V.; Szpilfogel, S.; Experientia 1945, 1, 197.

20. Prelog, V.; Zalán, E.; Helv. Chim. Acta 1944, 27, 535.

21. Prelog, V.; Wieland, P.; Helv. Chim. Acta 1944, 27, 1127.

22. Janot, M.-M.; Goutarel, R.; Prelog, V.; Helv. Chim. Acta 1951, 34, 1207.

23. Goutarel, R.; Janot, M.-M.; Prelog, V.; Taylor, W. I.; Helv. Chim. Acta 1950, 33, 150.

24. Prelog, V.; Angew. Chem. 1957, 69, 33.

25. Prelog, V.; Norymberski, J.; Jeger, O.; Helv. Chim. Acta 1946, 29, 360.

26. Prelog, V.; Jeger, O. Em The Alkaloids; Manske, R. F.; Holmes, H. L., eds.; Academic: Nova Iorque, 1953, vol. 3 e 7.

27. Barton. D. H. R.; Jeger, O.; Prelog, V.; Woodward, R. B.; Experientia 1954, 10,81 . 
28. Prelog, V.; Frenkiel, L.; Kobelt, M.; Barman, P.; Helv. Chim. Acta 1947, 30, 1741.

29. Prelog, V. Em Perspectives in Organic Chemistry; Todd, S. A., ed.; Interscience: Nova Iorque, 1956, p. 56.; Prelog, V.; Kobelt, M.; Helv. Chim. Acta 1949, 32, 1187.

30. http://nobelprize.org/nobel_prizes/chemistry/laureates/1969/bartonlecture.pdf\#search=\%22barton\%20nobel\%20lecture\%22, acessada em Outubro 2006

31. Prelog, V.; Ruzicka, L.; Barman, P.; Frenkiel, L.; Helv. Chim. Acta 1948, 31,92

32. Prelog, V.; Wiesner, K.; Helv. Chim. Acta 1947, 30, 1465.

33. Prelog, V.; Wiesner, K.; Helv. Chim. Acta 1948, 31, 877.

34. Ruzicka, L.; Plattner, P.; US 26563491953 (CA 48:77778).

35. Cope, A. C.; Martin, M. M.; McKervey, M. A.; Quart. Rev. 1966, 20, 119

36. Prelog, V.; Schenker, K.; Helv. Chim. Acta 1952, 35, 2044.

37. Heck, R.; Prelog, V.; Helv. Chim. Acta 1955, 38, 1541.

38. Brown, H. C.; Ham, G. J.; J. Am. Chem. Soc. 1956, 78, 5599.

39. Prelog, V.; Angew. Chem. 1958, 70, 145.

40. Anliker, R.; Dvornik, D.; Gubler, K.; Heusser, H.; Prelog, V.; Helv. Chim. Acta 1956, 39, 1785.

41. Djerassi, C.; Halpern, O.; J. Am. Chem. Soc. 1957, 79, 3926.

42. Dominguez, J.; Dunitz, J. D.; Gerlach, H.; Prelog, H.; Helv. Chim. Acta 1962, 45, 129.

43. Keller-Schierlein, W.; Mihailoviæ, M. Lj.; Prelog, V.; Helv. Chim. Acta 1959, 42, 305.

44. Prelog, V.; Pure Appl. Chem. 1963, 6, 327.
45. Dunitz, J. D.; Hawley, D. M.; Mikloš, D.; White, D. N. J.; Berlin, Yu.; Marušic, R.; Prelog, V.; Helv. Chim. Acta 1971, 54, 1709.

46. Oppolzer, W.; Angew. Chem. 1984, 96, 840

47. Prelog, V.; Oppolzer, W.; Helv. Chim. Acta 1973, 56, 2279.

48. Comin, J.; Gonçalves de Lima, O.; Grant, H. N.; Jackman, L. M.; KellerSchierlein, W.; Prelog, V.; Helv. Chim. Acta 1963, 46, 409.

49. Prelog, V.; Helv. Chim. Acta 1953, 36, 308

50. Prelog, V.; Ceder, G.; Wilheim, M.; Helv. Chim. Acta 1955, 38, 303.

51. http://nobelprize.org/nobel_prizes/chemistry/laureates/1975/cornforthlecture.pdf\#search=\%22Cornforth\%20nobel\%20lecture\%22, acessada em ???

52. Cornforth, R. H.; Cornforth, J. W.; Prelog, V.; Liebigs Ann. Chem. 1960, 634, 197

53. Prelog, V.; Acklin, W.; Helv. Chim. Acta 1956, 39, 748; Dutler, H.; Coon, M. J.; Kull, A.; Vogel, H.; Waldvogel, G.; Prelog, V.; Eur. J. Biochem. 1971, 22, 213; Dutler, H.; van der Baan, J. L.; Hochuli, E.; Kis, Z.; Taylor, K. E.; Prelog, V.; Eur. J. Biochem. 1977, 75, 423.

54. Cahn, R. S.; Ingold, C. K.; Prelog, V.; Experientia 1956, 12, 81.

55. Klyne, W.; Prelog, V.; Experientia 1960, 16, 521.

56. Prelog, V.; Helmchen, G.; Angew. Chem. 1982, 94, 614.

57. Prelog. V.; Gerlach, H.; Helv. Chim. Acta 1964, 47, 2288.

58. Prelog, V.; Thix, J.; Srikrishnan, T.; Helv. Chim. Acta 1982, 65, 2622.

59. Haas, G.; Prelog, V.; Helv. Chim. Acta 1969, 52, 1202.

60. Prelog, V.; Bedeković, D.; Helv. Chim. Acta 1979, 62, 2285.

61. Prelog, V.; Stojanac, Ž.; Kovačević, K.; Helv. Chim. Acta 1982, 65, 377.

62. Prelog, V.; My 132 Semesters of Chemistry Studies, American Chemical Society: Washington DC, 1991. 